\title{
Justiça organizacional e o estresse no trabalho de bancários
}

\author{
Tarízi Cioccari Gomes ${ }^{1, *}$, Vania de Fátima Barros Estivalete ${ }^{1}$, \\ Amanda Oliveira Ramadam ${ }^{1}$
}

\section{Resumo}

O objetivo desta pesquisa foi analisar as relações entre a justiça organizacional e o estresse no trabalho, segundo a perspectiva dos funcionários do setor bancário público e privado de uma cidade do estado do Rio Grande do Sul, no Brasil. Para isso, foi realizado um estudo com 339 colaboradores de instituições bancárias, adotando-se como instrumentos de pesquisa a Escala de Percepção de Justiça Organizacional, a Escala de Estresse no Trabalho e a versão reduzida da Escala de Desequilíbrio Esforço-Recompensa. A análise dos dados ocorreu através de estatística descritiva, indicador de alfa de Cronbach, testes de normalidade, teste Mann-Whitney, teste Kruskal-Wallis, teste Qui-Quadrado e Análise de Correspondência. Como resultados, evidencia-se a relação entre a percepção de justiça organizacional e o estresse no trabalho, demonstrando que a percepção de justiça contribui para a forma com que os colaboradores encaram as situações e as demandas de trabalho, que podem levar ao estresse.

Palavras-chave: justiça organizacional, estresse no trabalho, percepção, bancários.

\section{Organizational Justice and Stress at Work of Bankers}

\section{Justicia Organizacional y el estrés en el trabajo de los bancos}

\section{Resumen}

El objetivo de esta investigación fue analizar la relación entre la justicia organizacional y el estrés laboral, desde la perspectiva de los empleados del sector bancario público y privado de una ciudad en el estado de Rio Grande do Sul, Brasil. Para esto, se realizó un estudio con 339 empleados de instituciones bancarias, adoptando como instrumentos de investigación la Escala de Percepción de Justicia Organizacional, la Escala de Estrés en el Trabajo y la versión reducida de la Escala de desequilibrio de esfuerzo-recompensa. El análisis de los datos se realizó mediante estadística descriptiva, indicador alfa de Cronbach, pruebas de normalidad, prueba de Mann-Whitney, prueba de Kruskal-Wallis, prueba de Chi-cuadrado y análisis de correspondencia. Como resultado, se evidencia la relación entre la percepción de justicia organizacional y el estrés en el trabajo, lo que demuestra que la percepción de justicia contribuye a la forma en que los empleados enfrentan situaciones y demandas laborales que pueden generar estrés.

Palabras-clave: justicia organizacional, estrés en el trabajo, percepción, banco. 
No ambiente organizacional, especialmente no setor bancário, os colaboradores têm sofrido diversas pressões, exercidas tanto pelos gestores quanto por seus próprios colegas de trabalho. Percebe-se que essa realidade passou a mudar a qualidade de vida dos trabalhadores, fazendo surgir sintomas de ansiedade, depressão, exaustão e estresse aos indivíduos (Capitão, Romaro, \& Silva, 2010). Desse modo, os trabalhadores reagem de diversas formas, as quais podem ser resultantes de percepções a respeito da identificação de justiça organizacional a que são submetidos. Na literatura, há diversas relações da temática de percepção de justiça organizacional com outros fatores envolvendo os comportamentos dos indivíduos e da organização, entre eles a satisfação (Heron, Coseano, \& Bruk-Lee, 2018), os comportamentos de cidadania organizacional (Lim \& Loosemore, 2017) e o estresse no trabalho (Inoue, Kawakami, Tsutsumi, Shimazu, \& Tsuchiya, 2009; Judge \& Colquitt, 2004; Pérez-Rodríguez, Topa, \& Beléndez, 2019; Poole, 2007; Silva, 2010).

Os estudos de Akram, Lei, Haider, Hussain e Puig (2017) identificaram que todas as configurações de justiça organizacional (distributiva, processual, interacional, temporal e espacial) têm um impacto envolvendo o compartilhamento de conhecimentos na organização. Percebe-se que a justiça organizacional deve ser colocada em uma posição importante na cultura da organização e na produção de resultados, visto que os colaboradores definem sua postura de trabalho com base no tratamento recebido (Heron et al., 2018). Se o colaborador percebe que a empresa toma decisões justas, isso pode contribuir para uma relação mais profunda entre indivíduo e organização (Heron et al., 2018).

Quando há crença de que as necessidades socioemocionais dos colaboradores são satisfeitas e que se percebe o cuidado com isso, pode haver um sentimento de obrigação em compensar o ágio por meio do envolvimento em comportamentos benéficos que promovam a performance eficaz da equipe (Lim \& Loosemore, 2017). Portanto, torna-se importante que as organizações adotem estratégias eficazes para ajudar os colaboradores a lidar com a insegurança no contexto de trabalho, pois, ao perceberem que a organização tem senso de justiça, os funcionários podem reduzir seu nível de estresse e manter o afeto positivo com o trabalho (Wang, Lu, \& Siu, 2015).

Ao perceber que fazem parte de um determinado grupo e que não são injustiçados, os colaboradores contribuem com a organização, mas, caso haja sensação de injustiça em relação aos procedimentos e à atuação em decisões tomadas, isso pode fomentar o sofrimento. Nota-se que as relações recíprocas indivíduo-organização devem ser consideradas. A organização pode fornecer suporte para assegurar o bem-estar pessoal dos colaboradores, evitando o estresse e outros fatos decorrentes disso (Paz, Gosendo, Dessen, \& Mourão, 2009). É primordial que os gestores compreendam as percepções de justiça dos indivíduos, assim como o comportamento dos colaboradores quando percebem que estão recebendo tratamento injusto, visto que tais ações podem afetar negativamente a efetividade organizacional (Mendonça, 2003).

A fim de compreender melhor o comportamento dos indivíduos no trabalho bancário, este estudo propõe uma abordagem preventiva, visto que se objetiva amenizar/reduzir problemas decorrentes de relacionamentos no contexto organizacional, conflitos e dificuldades emocionais influenciados pelo sentimento de justiça organizacional e o estresse no trabalho.

A gestão bancária deve considerar a relevância que a justiça organizacional tem na organização, a fim de elevar a satisfação e o nível de comprometimento dos funcionários, assim como impactar de modo positivo no desempenho organizacional (Ali \& Saifullah, 2014). Os serviços que os bancos oferecem são de grande importância para o desenvolvimento econômico mundial, o que torna necessário que os colaboradores desse setor sejam valorizados, de modo que desempenhem melhor suas funções (Lima, Machado, Carneiro, \& Macedo, 2019).

Partindo dessas considerações, a presente pesquisa almeja responder ao seguinte problema: de que forma ocorre a relação entre a percepção de justiça organizacional e o estresse no trabalho, segundo a perspectiva dos funcionários do setor bancário público e privado? Para responder a tal questionamento, o objetivo deste artigo é analisar as relações entre a justiça organizacional e o estresse no trabalho, segundo a perspectiva dos funcionários do setor bancário público e privado de uma cidade do estado do Rio Grande do Sul, Brasil.

\section{Justiça Organizacional e suas Dimensões}

Muitas são as aflições notadas no trabalho em relação à justiça organizacional e a como essas questões podem causar impactos nos comportamentos das pessoas, influenciando no desenvolvimento de estresse no ambiente laboral (Santos, Oliveira, \& Konopka, 2016). No século passado, os estudos sobre justiça se desenvolveram a partir da década de 1960, com as inestimáveis contribuições de George Homans e John Adams (Zarife, 2016). Homans, em 1961, apresentou a ideia de que o homem espera receber suas recompensas de forma proporcional às relações de troca que estabelece com seus colegas (Mendonça \& Tamayo, 2004).

No final da década de 1980, Greenberg denominou de justiça organizacional a literatura sobre compreensão e atitudes dos trabalhadores frente à (in)justiça no ambiente organizacional (Zarife, 2016). Segundo Greenberg (1993), a justiça organizacional exerce uma importante influência nas relações, de modo que se torna condição fundamental para o andamento eficaz das empresas e a satisfação dos seus membros.

Os estudos que abordam questões acerca da justiça no ambiente de trabalho estão em ascensão na área de comportamento organizacional (Akram et al., 2017). As questões que fazem referência à subjetividade, como as que estão envolvidas nos juízos de justiça, requerem atenção no que tange às relações entre colaboradores e suas organizações (Assmar, Ferreira e Souto, 2005). Os estudos provenientes da psicologia organizacional permitem compreender a justiça organizacional como um antecedente de comportamentos, afetos e atitudes nesse ambiente (Paz et al., 2009).

A justiça organizacional não deve ser compreendida como um fenômeno unidimensional, podendo referir-se a diversos aspectos organizacionais (Akram et al., 2017). Neste estudo, optou-se por analisar a justiça organizacional mediante três dimensões: justiça distributiva, justiça processual e justiça interacional (Assmar et al., 2005; Mendonça, 2003). Entre as pesquisas sobre justiça organizacional destaca-se a utilizada neste estudo, desenvolvida por Mendonça, Pereira, Tamayo e Paz (2003), que construiu e validou um instrumento a fim de medir a percepção de justiça organizacional do trabalhador no contexto nacional, denominado Escala de Percepção de Justiça Organizacional (EPJO), que constatou que a justiça organizacional é formada pelas dimensões citadas anteriormente.

A justiça distributiva refere-se à distribuição de recompensas, sejam elas positivas ou negativas (Akram et al., 2017; Assmar et al., 2005). A justiça processual concerne aos procedimentos que as organizações estabelecem para tomar decisões ou resolver conflitos (Akram et al., 2017; Assmar et al., 2005). A justiça interacional, por sua vez, está relacionada à equidade no tratamento interpessoal, referindo-se às relações entre decisores e suas equipes de trabalho (Akram et al., 2017; Assmar et al., 2005). Estudos demonstram que o entendimento das dimensões de justiça deve afetar nos efeitos do estresse no trabalho (Judge \& Colquitt, 2004). 


\section{Estresse no Trabalho}

É possível observar um crescente interesse por parte dos pesquisadores em relação ao impacto considerável do estresse psicológico na saúde dos indivíduos (Soares, Mafra, \& Farias, 2018). O conceito de "estresse" não é novo. Hans Selye foi um dos primeiros estudiosos a se debruçar sobre o tema, focando em sua dimensão biológica. O autor concluiu que o estresse é um elemento inerente a toda doença, que produz alterações na composição química do corpo (Filgueiras \& Hippert, 1999).

O estresse pode ser classificado de diferentes maneiras: o ocupacional está vinculado ao cargo que o indivíduo ocupa e faz referência às dificuldades exigidas por sua tarefa, enquanto o organizacional refere-se ao estresse concernente à empresa na qual o indivíduo atua (Zarife, 2016). As condições externas e o ambiente de trabalho podem interferir na presença dos efeitos negativos do estresse, desenvolvendo o chamado estresse ocupacional (Soares et al., 2018).

O estresse no ambiente laboral pode estar relacionado a fatores do trabalho que ultrapassam a capacidade dos colaboradores ou, ainda, às respostas fisiológicas, psicológicas e comportamentais (Santos et al., 2016).

$\mathrm{O}$ aumento do interesse tanto acadêmico quanto popular sobre o estresse deve-se às comprovações de sua influência nos aspectos físico, emocional e social, além da identificação de eventos estressores nos mais variados contextos (Zarife, 2016). O ambiente de trabalho é um local importante para a promoção da saúde e do bem-estar dos funcionários (Kivimäki \& Kawachi, 2015). Nesse sentido, diversas instituições, tanto nacionais quanto internacionais, têm a incumbência de assegurar a saúde e a segurança dos trabalhadores, identificando os riscos físicos, químicos e biológicos possíveis no espaço laboral. Percebe-se que, de modo gradativo, tem-se dado maior atenção ao local de trabalho psicossocial, com enfoque no estresse do trabalho (Kivimäki \& Kawachi, 2015).

No Brasil, as doenças provenientes de fontes de riscos ergonômicos e de sobrecarga mental são as principais razões de absenteísmo e afastamento do trabalho, ultrapassando os fatores traumáticos (Coelho, Souza, Cerqueira, Esteves, \& Barros, 2018). Abordagens atuais fornecem contribuições cruciais para um esclarecimento da origem fisiológica para o estresse, por meio de respostas fisiológicas e adaptação às demandas e aos estressores, incluindo o sistema nervoso e suas interações com os componentes do sistema imunológico (Coelho et al., 2018). Assim, deve-se levar em consideração questões mais detalhadas sobre as funções e as atividades executadas pelos bancários e a carga horária de trabalho, entre outros fatores que poderiam ser pesquisados (Coelho et al., 2018).

No que tange ao estresse no setor bancário, há necessidade da proposição de estratégias organizacionais que visemà reestruturação de processos, proporcionando maior autonomia ao colaborador e reduzindo demandas contraditórias, minimizando, assim, o estresse no trabalho e seu impacto na saúde do indivíduo (Petarli, Zandonade, Salaroli, \& Bissoli, 2015). Ressalta-se que os níveis de estresse e burnout, em muitas organizações, podem aumentar devido aos baixos níveis de justiça organizacional (Dishon-Berkovits, 2018).

\section{Método}

\section{Participantes}

A cidade pesquisada tem três bancos públicos e quatro bancos privados, segundo informações do Sindicato dos Bancários da região. Os bancos públicos empregavam 513 colaboradores, enquanto os privados apresentavam 162 no momento de realização da pesquisa. Como critério de inclusão, foram considerados os colaboradores ativos nas instituições bancárias da cidade, abrangendo as diversas nomenclaturas de carreiras des- sa categoria. Como critério de exclusão, não participaram da pesquisa colaboradores que se encontravam em férias ou demais afastamentos legais durante o período de coleta de dados.

Obteve-se um retorno de $51,11 \%$ de questionários preenchidos, representados pelo $n=345$. No entanto, após a revisão do preenchimento dos instrumentos utilizados, foram excluídos 6 questionários, totalizando $n=339$, compreendendo $50,22 \%$ de respostas.

\section{Instrumentos}

Inicialmente, foram elaboradas questões sociodemográficas, incluindo informações de sexo, idade, estado civil, renda, escolaridade, número de filhos e setor bancário, a fim de traçar um panorama geral do perfil dos bancários. Posteriormente, para atender ao objetivo da pesquisa, foram utilizados três instrumentos com o intuito de verificar a relação entre as temáticas de justiça organizacional e estresse no trabalho. Optou-se em adotar, na presente pesquisa, uma escala de justiça organizacional (a EPJO) e duas escalas para avaliar o estresse no trabalho (Escala de Estresse no Trabalho [EET] e Escala de Desequilíbrio Esforço-Recompensa [DER]), pois cada uma comtempla diferentes construtos que, de modo conjunto, possibilitaram uma análise mais consistente.

A primeira medida foi a EPJO, desenvolvida por Mendonça et al. (2003), com 20 itens organizados em três dimensões: justiça distributiva (seis itens), justiça processual (sete itens) e justiça interacional (sete itens). As afirmações são avaliadas por meio de uma escala do tipo Likert, atribuindo-se valores de um a cinco (discordo totalmente a concordo totalmente). A EPJO obteve valores do alfa de Cronbach, nas dimensões justiça distributiva, processual e interacional, de 0,88, 0,87 e 0,89, respectivamente (Mendonça et al., 2003).

A segunda escala adotada foi a EET, desenvolvida por Karasek (1985) e Theörell (1988), validada no Brasil por Alves, Chor, Faerstein, Lopes e Werneck (2004), com 17 itens organizados em três dimensões: demanda psicológica (cinco itens), controle (seis itens) e apoio social (seis itens). As afirmações são avaliadas por meio de uma escala do tipo Likert, atribuindo-se valores de um a quatro (frequentemente a nunca/quase nunca) para as dimensões demanda psicológica e controle e, para a dimensão apoio social, também foi utilizada uma escala do tipo Likert de 4 pontos (concordo totalmente a discordo totalmente). A consistência interna da escala EET, na pesquisa de Alves et al. (2004), apresentou valores do alfa de Cronbach, para as dimensões demanda psicológica, controle e apoio social, de 0,79, 0,67 e 0,85, respectivamente.

A terceira escala utilizada foi a DER, desenvolvida por Siegrist, Wege, Pühlhofer e Wahrendorf (2009) e validada em contexto nacional por Chor, Werneck, Faerstein, Alves e Rotenberg (2008), composta por 16 itens, organizados em três dimensões: esforço (três itens), recompensa (sete itens) e excesso de comprometimento (seis itens). As afirmações são avaliadas por meio de uma escala do tipo Likert, atribuindo-se valores de um a quatro (discordo totalmente a concordo totalmente). A DER obteve valores do alfa de Cronbach, nas dimensões esforço, recompensa e excesso de comprometimento, de 0,74, 0,79 e 0,79, respectivamente.

\section{Procedimentos de Coleta de Dados e Cuidados Éticos}

De posse do instrumento contendo as questões de perfil, a EPJO, a EET e a DER, para a aplicação dos questionários, as pesquisadoras contataram os funcionários dos bancos para convidá-los a participar da investigação de maneira livre e voluntária, anônima, sem custos ou compensação financeira, mediante a autorização prévia do gestor responsável. A forma de aplicação foi individual, com uso de questionário impresso, entregue diretamente aos funcionários nos bancos pesquisados. Os partici- 
pantes foram esclarecidos a respeito dos objetivos da pesquisa, e foi garantido o seu anonimato. Após uma semana, e, posteriormente, em duas semanas, os questionários foram recolhidos nas agências bancárias até que se tivesse o retorno mínimo esperado.

Além disso, os trabalhadores pesquisados foram informados da confidencialidade dos dados e da necessidade da assinatura do Termo de Consentimento Livre e Esclarecido (TCLE), que foi entregue aos respondentes juntamente com o questionário, esclarecendo-se o propósito da pesquisa e a importância da sua realização. Ressalta-se que esta pesquisa foi encaminhada ao Comitê de Ética em Pesquisa da Universidade Federal de Santa Maria, para que fosse autorizada a coleta e a análise dos dados, sendo aprovada com o número de registro do parecer 81034.

\section{Procedimentos de Análise de Dados}

Os dados foram tabulados e analisados, com auxílio de quatro softwares: Statistical Package for the Social Sciences 16.0 (SPSS), Microsoft Office Excel 2007, Statistical Analisys Systems (SAS) versão 9 e Statistica versão 6. As análises dos instrumentos ocorreram por meio da medição das dimensões e dos fatores, com testes estatísticos descritivos (frequências, médias, medianas e desvio-padrão), indicador de consistência interna alfa de Cronbach e testes de normalidade.

Nas três escalas utilizadas (EJPO, EET e DER), foram realizados testes não paramétricos. As dimensões da DER foram analisadas de acordo com a frequência das respostas e de comparação de grupos (Mann-Whitney e Kruskal-Wallis), e o teste Qui-Quadrado devido a não normalidade dos dados. As dimensões da EET com valores acima da mediana foram avaliadas e classificadas como "altas"; e as com valores abaixo da mediana como "baixas". O cálculo da razão entre a demanda e o controle foi definindo em: "baixo desgaste", "alto desgaste", "trabalho ativo" e "trabalho passivo".

Com isso, a partir dos resultados obtidos com a EPJO, a EET e a DER, foi realizada a análise de correspondência simples. A representação gráfica da análise de correspondência pode ser realizada por meio de um gráfico de dispersão das principais coordenadas das linhas e colunas, chamado de gráfico de correspondência, que tem o objetivo de analisar a associação existente (Mingoti, 2005). A Figura 1 apresenta as etapas do método adotado nesta pesquisa.

\section{Resultados e Discussão}

Inicialmente, foi possível identificar o perfil dos bancários pesquisados. O número de respondentes do sexo masculino foi de 49,85\% (169 colaboradores) e do sexo feminino, de $50,15 \%$ (170 colaboradoras). Indivíduos com filhos representaram 62\% dos pesquisados. Quanto ao setor, 66\% integram o setor público e $34 \%$ o privado. Em relação à idade, a média foi de 38 anos. Grande parte dos respondentes é casado (59\%), ficando o estado civil solteiro em segundo lugar (29\%). A maioria dos pesquisados tem graduação $(62 \%)$ e especialização $(24 \%)$.

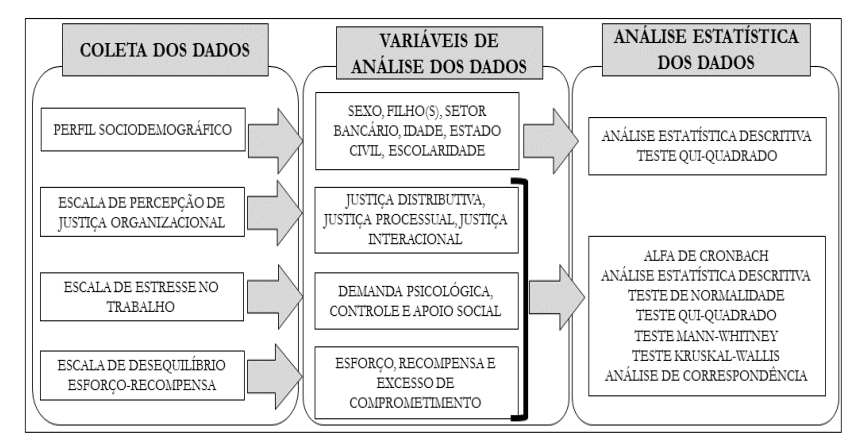

Figura 1. Etapas da coleta e análise dos dados. Fonte: elaborada pelas autoras.
Os instrumentos utilizados possibilitaram a análise de correspondência, necessária para verificar a intensidade da relação entre a justiça organizacional e o estresse no trabalho.

Considerando que a baixa justiça organizacional representa um risco para os trabalhadores (Elovainio, Kivimäki, \& Vahtera, 2002), assim como o estresse no trabalho (Karasek \& Theörell, 1990), buscou-se analisar as relações entre esses dois construtos, segundo a perspectiva dos funcionários do setor bancário público e privado. No contexto organizacional, o estresse pode estar relacionado a fatores do trabalho que extrapolam a capacidade das pessoas ou às respostas fisiológicas, psicológicas e comportamentais dos colaboradores diante de estressores (Santos et al., 2016). A maior inquietação refere-se à verificação dos estressores, os quais representam os eventos que provocam respostas alusivas ao estresse, que impactam no bem-estar e no desempenho (Santos et al., 2016).

A literatura sobre a percepção de justiça vislumbra aspectos que podem apresentar relações com o estresse no trabalho. Essa afirmação é corroborada pelos estudos de Judge e Colquitt (2004), Poole (2007), Inoue et al. (2009), Silva (2010), Dishon-Berkovits (2018) e Pérez-Rodríguez et al. (2019), os quais apresentam associações entre fatores que levam ao estresse no trabalho e à percepção de justiça organizacional.

A seguir, por meio da análise de correspondência, apresenta-se as relações, em bancos públicos e privados, entre a EPJO e a EET, e, após, as relações entre a EPJO e a DER. Por fim, são demonstradas e discutidas as relações entre as três escalas (EPJO, EET e DER).

Ao analisar as dimensões da EPJO (justiça distributiva, processual e interacional) e da EET (demanda psicológica, controle e apoio social), no setor bancário público, constatou-se a existência de fortes relações entre as dimensões de justiça e as dimensões controle e apoio social da EET.

De maneira semelhante a esse resultado, as baixas percepções de justiça organizacional apontaram grande associação com o baixo controle e o baixo apoio social.

Apesar de terem ocorrido significativas relações entre as escalas, as dimensões da EPJO não apresentaram forte associação com a dimensão demanda psicológica da EET em bancos públicos. Esse resultado pressupõe que, embora haja aumento da exigência e das demandas no trabalho, a demanda psicológica, que se refere ao tempo de realização das atividades (Alves et al., 2004), não apresentou relação com o controle de suas atividades, o apoio social de colegas e chefias e com as dimensões da justiça organizacional.

O setor bancário privado configura-se de maneira semelhante ao setor público, uma vez que apresentou altas percepções de justiça organizacional vinculadas às dimensões baixa demanda psicológica e alto apoio social da EET. Como citado anteriormente, a percepção de justiça organizacional está relacionada ao baixo investimento psicológico dos bancários no contexto do trabalho (como pressão do tempo, interrupção das atividades e nível de concentração) e ao alto apoio social. Esses dados vão ao encontro do que afirmam Judge e Colquitt (2004, p. 396), os quais consideram que os fatores de estresse no trabalho, como conflitos interpessoais, restrições organizacionais, relacionamentos com superiores e falta de apoio social, parecem "capturar, em parte, as facetas interpessoais e informacionais da justiça organizacional”. Evidencia-se que a percepção de justiça organizacional, considerando suas três dimensões, está relacionada ao apoio social e à baixa demanda psicológica.

Destaca-se que as dimensões de justiça organizacional não apresentaram relação significativa com as dimensões controle (alto e baixo) e alta demanda psicológica, nem no setor público nem no privado. Segundo Poole (2007), as pesquisas referentes à justiça processual evidenciam que o controle (autoridade) na tomada de decisão apresenta uma relevante contribuição para as percepções de justiça. No entanto, na presente pesquisa, a justi- 
ça processual e o controle no trabalho não apresentaram qualquer relação estatisticamente significativa nos bancos públicos.

Ao se analisar comparativamente os dados das relações da EPJO e da EET em colaboradores dos diferentes setores bancários, pode-se perceber que houve uma diferenciação entre as percepções. Nos bancos públicos, as dimensões da justiça organizacional não apresentaram relação estatisticamente significativa com a demanda psicológica, enquanto, em bancos privados, as dimensões da justiça organizacional não tiveram relação significativa com o controle das atividades de trabalho e a alta demanda psicológica.

Ao se analisar as dimensões da EPJO (justiça distributiva, processual e interacional) e da DER (esforço, recompensa e excesso de comprometimento), no setor bancário público e privado, percebe-se que as altas percepções de justiça organizacional se associaram significativamente com a dimensão recompensa da DER.

Além disso, no setor bancário público, constatou-se relação entre as baixas percepções de justiça organizacional (processual, interacional e distributiva) e a baixa recompensa. A falta de reconhecimento, de acordo com Silva (2010, p. 331), "é indicada pela vivência de injustiça, indignação e desvalorização pelo não reconhecimento do trabalho realizado".

Essas constatações confirmam os dados encontrados por Judge e Colquitt (2004), os quais afirmam que a justiça processual e a interpessoal possuem significativos efeitos totais no estresse. A justiça de procedimentos envolve elementos formais, incluindo os métodos que norteiam os processos organizacionais, como a avaliação de desempenho e a fixação de metas, enquanto a justiça interacional engloba as relações entre gestores e subordinados, notadamente sobre explicação de resultados alcançados, permitindo uma maior autonomia do que a justiça de procedimentos (Zarife, 2016).

No entanto, no setor bancário privado, as baixas percepções de justiça não apontaram relação com a baixa recompensa. Verifica-se, assim, que a maioria dos resultados encontrados corrobora a literatura, visto que quando o colaborador sente que não foi recompensado de forma correta, que foi injustiçado, ele tende a desenvolver sentimento de impotência, raiva e decepção que podem gerar o estresse (Pérez-Rodríguez et al., 2019).

A fim de verificar as relações entre as três escalas utilizadas neste estudo, foi realizada a análise de correspondência entre as dimensões da EPJO e os modelos teóricos da EET e da DER, nos dois setores bancários. Para fins de análise das relações, foi utilizado o modelo demanda-controle da EET, de acordo com as pontuações das questões "baixo desgaste", "alto desgaste", "trabalho ativo" e "trabalho passivo", bem como foi utilizado o modelo desequilíbrio esforço-recompensa da DER, conforme as intensidades, identificadas por meio de uma fórmula, classificadas como "baixo DER" e "alto DER".

Pode-se verificar que, no setor bancário público, a baixa percepção de justiça distributiva apresentou associação estatística com o "alto DER" (desequilíbrio esforço-recompensa), o "trabalho passivo" e o "alto desgaste". Assim, os colaboradores que percebem baixa justiça distributiva na organização consideram também os níveis de demanda psicológica e de controle no trabalho, o que pode torná-los apáticos diante das situações e deixá-los expostos ao adoecimento físico e psíquico devido à elevada exposição ao estresse.

Em contrapartida, a alta percepção de justiça distributiva está relacionada com o "baixo DER" e o "baixo desgaste". Indivíduos que percebem alta justiça distributiva na organização consideram que há baixo desequilíbrio entre o que investem na empresa e o que recebem, percepção que está relacionada com os baixos níveis de demanda psicológica e com o alto controle no processo de trabalho (considerado estado "ideal" - "baixo desgaste"). A justiça distributiva influencia de modo negativo o estresse no trabalho, de modo que a percepção de regras, políticas e procedimentos injustos pelas pessoas causa impacto direto na satisfação com o trabalho (Santos et al., 2016).

O "trabalho ativo" não apresentou relação com a justiça distributiva em bancos públicos. No setor bancário privado, as relações visualizadas foram menos intensas, pois os dados apresentaram-se mais dispersos. Evidencia-se que não foram apontadas fortes associações entre baixa percepção de justiça distributiva, "alto DER", "alto desgaste", "trabalho passivo" e "trabalho ativo". Contudo, assim como foi visto no setor público, a alta percepção de justiça distributiva apresentou relação significativa estatisticamente com o "baixo desgaste" e o "baixo DER", contribuindo para o bem-estar da saúde psíquica do trabalhador, reduzindo os possíveis danos. A justiça distributiva vincula-se ao reconhecimento das atitudes dos trabalhadores e está relacionada a emoções positivas, que podem evitar o estresse no contexto laboral (Pérez-Rodríguez et al., 2019).

No que tange às relações entre a percepção de justiça processual e os modelos teóricos de estresse, pode-se perceber que, no setor bancário público, a baixa percepção de justiça processual tem relação com o "alto DER", o "trabalho passivo" e o "alto desgaste", enquanto a alta percepção de justiça processual apresentou relação significativa com o "baixo DER" e o "baixo desgaste". A justiça processual abrange o direito em expor opiniões, a representatividade na tomada de decisões, os critérios para as decisões, o feedback e a coleta de informações a respeito dos problemas da organização (Mendonça, 2003).

No setor bancário privado, as relações foram praticamente as mesmas ocorridas no setor público, apresentando diferença no que tange ao trabalho passivo, o qual não esteve relacionado à justiça processual. A baixa percepção de justiça processual associa-se com o "alto DER" e o "alto desgaste", enquanto a alta percepção de justiça processual relaciona-se ao "baixo DER" e ao "baixo desgaste". Segundo Judge e Colquitt (2004), é pertinente frisar que a justiça processual e a interpessoal representam os principais efeitos da justiça, visto que elas têm consequências sobre a percepção de estresse.

Ao se analisar a associação entre a dimensão justiça interacional e os modelos de estresse, pode-se observar que, em bancos públicos, as relações foram semelhantes às encontradas na relação com a justiça processual. Desse modo, a baixa percepção de justiça interacional está associada ao "alto DER", ao "trabalho passivo" e ao "alto desgaste", assim como houve associações entre a alta percepção de justiça interacional, o "baixo DER” e o "baixo desgaste". Dessa forma, ressalta-se o entendimento de Judge e Colquitt (2004), que, ao citarem diversos autores, afirmam que as implicações para a justiça interpessoal estão consolidadas nos modelos de estresse, os quais têm estressores interpessoais, como desentendimentos com os colegas de trabalho, líderes inadequados, comportamentos ruins da supervisão ou pouco suporte do líder.

No setor bancário privado, as relações também se repetiram, visto que a baixa percepção de justiça interacional apresentou associação com o "alto DER" e o "alto desgaste", enquanto a alta percepção de justiça interacional relacionou-se com o "baixo DER” e com o "baixo desgaste". Esses dados demonstram que os colaboradores que percebem interação adequada com as chefias na condução dos procedimentos, nos relacionamentos interpessoais e no fornecimento de informações identificam baixo desequilíbrio entre o esforço gasto e a recompensa recebida, ao mesmo tempo em que se encontram no estado de equilíbrio em relação à baixa demanda psicológica e ao alto controle sobre as atividades de trabalho.

Contudo, os indivíduos que identificaram baixa justiça interacional estão mais sujeitos a riscos e podem adoecer em virtude dessa exposição. Para Jonge, Bosma, Peter e Siegrist (2000), o modelo desequilíbrio esforço-recompensa pode gerar uma situação de sofrimento emocional e ocasionar riscos cardiovasculares e tensões.

Poucas pesquisas foram realizadas com o intuito de verificar 
a relação existente entre a percepção de justiça organizacional e os fatores ou as dimensões que avaliam o estresse no trabalho. Entre os estudos, destaca-se a de Inoue et al. (2009), que constatou que os níveis mais altos de justiça processual e interacional tinham correlação com a menor tensão no trabalho, maior coleguismo e suporte do supervisor, maior recompensa e menor desequilíbrio entre esforço-recompensa entre os homens. Já no sexo feminino, a maior justiça processual e a interacional estava correlacionada a menores demanda de trabalho, esforço e desequilíbrio esforço-recompensa e a níveis mais altos de recompensa e suporte da chefia. A justiça interpessoal elevada também apresentou correlação com o alto apoio dos colegas de trabalho (Inoue et al., 2009).

Destaca-se que o "trabalho ativo" não apresentou associação com as intensidades "alta" e "baixa" do modelo desequilíbrio esforço-recompensa da DER e com as dimensões de justiça organizacional (distributiva, processual e interacional). Desse modo, os resultados revelam o caráter multidimensional da justiça organizacional e do estresse no trabalho, visto que apresentam uma série de relações entre as dimensões e os modelos teóricos. A Figura 2 expõe a síntese das relações de percepção de justiça organizacional e do estresse no trabalho em bancos públicos e privados.

Percebe-se que os temas estudados foram pertinen- à saúde dos trabalhadores. Entre eles, o estresse ocupacional é um dos riscos que compromete o bem-estar do indivíduo".

Com isso, os resultados obtidos nas relações entre os construtos evidenciam que a percepção de justiça organizacional repercute na forma de avaliação dos fatores que levam ao estresse no trabalho.

\section{Considerações Finais}

A realização desta pesquisa possibilitou analisar as relações entre a justiça organizacional e o estresse no trabalho, segundo a perspectiva dos funcionários do setor bancário público e privado de uma cidade do estado do Rio Grande do Sul, no Brasil. A análise dos dados confirmou a existência dessa relação e atingiu o objetivo proposto, visto que, de acordo com a primeira associação analisada, as percepções de justiça (distributiva, processual e interacional) dos trabalhadores de bancos públicos estavam associadas significativamente às dimensões controle e apoio social da EET. De modo semelhante, em bancos privados, as percepções de justiça (distributiva, processual e interacional) estiveram relacionadas às dimensões demanda psicológica e apoio social da EET. Nos dois setores bancários, as três dimensões de justiça se relacionaram com a dimensão recompensa da DER.

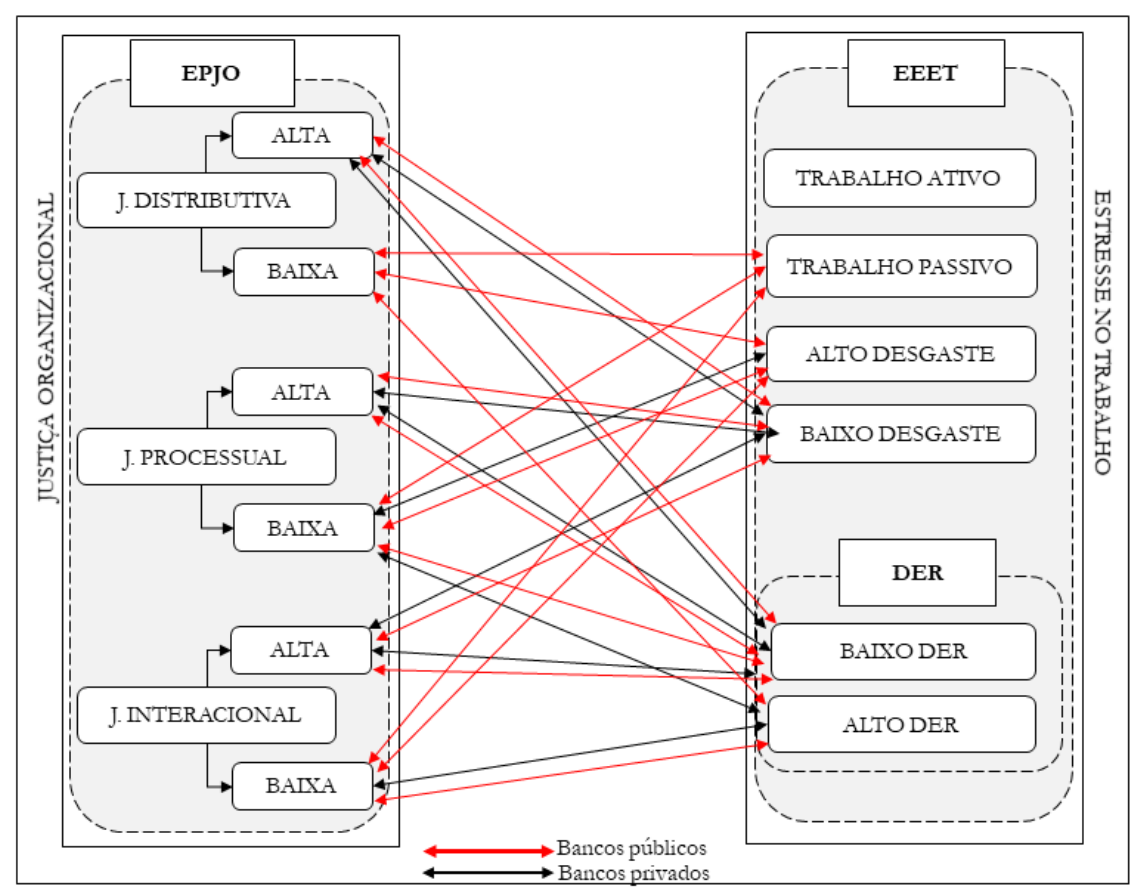

Figura 2. Síntese das relações entre as dimensões da EPJO e os modelos demanda-controle da EET e desequilíbrio esforço-recompensa da DER em bancos públicos e privados. Fonte: elaborado pelas autoras, com base nos resultados da pesquisa.

tes devido a sua importância no contexto organizacional e a sua influência para o desempenho das atividades laborais. Os resultados de justiça organizacional e de estresse no trabalho de ambos os setores se aproximaram.

A percepção de justiça dos colaboradores contribui para a compreensão e a forma de lidar com as situações e os conflitos de trabalho e, assim, com os elementos que levam ao estresse e ao adoecimento físico e mental. No caso desta pesquisa, entre os fatores do estresse, destacam-se a demanda psicológica e o controle no trabalho, bem como o esforço gasto e a recompensa recebida pelo trabalho desempenhado. A afirmação de Koltermann, Tomasi, Horta e Koltermann (2010, p. 34) fortalece o exposto, na medida em que o "trabalho é essencial para a vida humana, mas é também fonte de múltiplos riscos
Assim, os resultados das relações de justiça e de estresse de ambos os setores se aproximaram, o que tornou possível constatar que os indivíduos consideram a demanda psicológica, o controle, o apoio social e a recompensa quando avaliam a percepção de justiça organizacional.

Em relação à justiça organizacional e aos modelos das escalas de estresse (EET e DER), pode-se perceber que houve importantes relações, principalmente entre as altas percepções de justiça (distributiva, processual e interacional) e o estado ideal referente ao estresse no trabalho, denominado "baixo desgaste". Os resultados destacam a importância de os colaboradores visualizarem que há justiça nas organizações, pois isso repercute em um desgaste menor dos indivíduos, representando uma relação direta com alto e baixo estresse. Além disso, segundo os resultados obtidos na 
pesquisa, houve relação entre a baixa percepção de justiça, o alto desgaste e o alto desequilíbrio entre o esforço que o indivíduo investe no trabalho e a recompensa que ele recebe (alto DER), ocasionando maior risco de enfermidades e maior vulnerabilidade às doenças, o que causa danos para a saúde dos indivíduos.

Em geral, o adoecimento gera afastamentos no trabalho, doenças psíquicas, problemas nos relacionamentos, conflitos internos e interpessoais, entre outros, o que implica prejuízos, tanto financeiros quanto pessoais, para as instituições. Da mesma forma, se os colaboradores consideram que há equilíbrio entre um baixo esforço dispendido e uma alta recompensa, terão, com isso, menor risco de adoecimento, tensão e sofrimento emocional, desenvolvendo provavelmente comportamentos colaborativos com a instituição, aumento na satisfação e, consequentemente, melhor desempenho laboral.

Ainda, convém realçar que, em bancos públicos, as baixas percepções de justiça distributiva, processual e interacional apresentaram relações com o "trabalho passivo" dos colaboradores. Os indivíduos enquadrados no "trabalho passivo", segundo Karasek e Theörell (1990), tendem a ser apáticos devido à falta de desafios expressivos, o que pode causar desinteresse no trabalho. Assim, pode-se enfatizar que os indivíduos que não identificam a alta presença de justiça na organização podem tornar-se indiferentes às atividades laborais, gerando sentimentos negativos intensos e falta de sensibilidade e entusiasmo em trabalhar. Contudo, as três dimensões de justiça organizacional não se relacionaram com o "trabalho ativo" do modelo demanda-controle. O "trabalho ativo" pode levar os indivíduos a desenvolverem o seu potencial intelectual da melhor forma e possibilitar tomadas de decisão sobre as atividades de trabalho.

Os resultados ressaltam a necessidade de os gestores das instituições terem conhecimento da importância da justiça organizacional e do estresse no trabalho, a fim de que adotem políticas e práticas organizacionais com o intuito de aumentar a percepção de justiça, repercutindo na redução do estresse, e, consequentemente, em um melhor desempenho.

Partindo dessas colocações, a pesquisa trouxe contribuições teóricas a fim de elevar o conhecimento sobre as relações entre a justiça organizacional e o estresse no trabalho, bem como apresentou contribuições práticas, permitindo aos gestores de instituições bancárias acesso ao conhecimento das percepções dos colaboradores.

Esta pesquisa teve algumas limitações em seu desenvolvimento, como a realização em apenas uma cidade do estado do Rio Grande do Sul e somente sob a perspectiva da análise quantitativa, o que não permitiu análise dos resultados em grande profundidade a partir das respostas dos pesquisados.

Com base nos resultados da pesquisa, torna-se evidente que a associação entre a justiça organizacional e o estresse no trabalho necessita de maior investigação. Sugere-se, para investigações futuras, a realização de estudos envolvendo outras profissões, como trabalhadores das áreas da saúde, do ensino e de profissionais que atuam em situações de risco. Além disso, os temas abordados nesta pesquisa têm conexão com outras variáveis organizacionais que podem ser exploradas, como cultura organizacional, satisfação no trabalho, motivação, cidadania organizacional, suporte social, valores organizacionais e comprometimento organizacional.

\section{Referências}

Akram, T., Lei, S., Haider, M. J., Hussain, S. T., \& Puig, L. C. M. (2017). The effect of organizational justice on knowledge sharing: Empirical evidence from the Chinese telecommunications sector. Journal of Innovation \& Knowledge, 2, 134-145. https://doi.org/10.3389/fpsyg.2017.02315
Ali, M., \& Saifullah, Z. (2014). Distributive and Procedural Justice as Predictors of Job Satisfaction and Organizational Commitment: A Case Study of Banking Sector of Balochistan. European Journal of Business and Management, 6(34), 69-74. https://doi.org/10.7176/EJBM

Alves, M. G. M., Chor D., Faerstein E., Lopes C. S., \& Werneck G. L. (2004). Versão resumida da "Job Stress Scale": adaptação para o português. Rev Saúde Pública, 38(2), 164-171. https://doi.org/10.1590/S003489102004000200003

Assmar, E. M. L., Ferreira, M. C., \& Souto, S. (2005). Justiça Organizacional: Uma Revisão Crítica da Literatura. Psicologia: Reflexão e Crítica, 18(3), 443-453. https://doi.org/10.1590/S0102-79722005000300019

Capitão, C. G., Romaro, R. A., \& Silva, L. D. S. (2010). Estudo dos indicadores de estresse em gerentes de bancos. Revista Psicologia e Saúde, 2(2), 31-41.

Chor, D., Werneck, G. L., Faerstein, E., Alves, M. G. de M., \& Rotenberg, L. (2008). The Brazilian version of the effort-reward imbalance questionnaire to assess job stress. Cad. Saúde Pública, 24(1), 219-224. https://doi. org/10.1590/S0102-311X2008000100022

Coelho, J. A. P. M., Souza, G. H. S., Cerqueira, C. L. C., Esteves, G. G. L., \& Barros, B. N. R. (2018). Estresse como preditor da Síndrome de Burnout em bancários. Revista Psicologia: Organizações e Trabalho, 18(1), jan-mar, 306-315. https://doi.org/10.17652/rpot/2018.1.13162

Dishon-Berkovits, M. (2018). The Role of Organizational Justice and Stress in Predicting Job Burnout. Journal of Career Development, 45(5), 411-424. https://doi.org/10.1177/0894845317705469

Elovainio, M., Kivimäki, M., \& Vahtera, J. (2002). Organizational Justice: Evidence of a New Psychosocial Predictor of Health. American Journal of Public Health, 92(1), 105-108. https://doi.org/10.2105/AJPH.92.1.105

Filgueiras, J. C., \& Hippert, M. I. S. (1999). A polêmica em torno do conceito de estresse. Psicologia: ciência e profissão, 19(3), 40-51. https://doi.org/10.1590/ $\underline{\text { S1414-98931999000300005 }}$

Greenberg, J. (1993). Stealing in the name of justice: Informational and interpersonal moderators of theft reactions to underpayment inequity. Organizational Behavior and Human Decision Processes, 54, 81-103. https://doi.org/10.1006/ obhd.1993.1004

Heron, L., Coseano, R., \& Bruk-Lee, V. (2018). The Indirect Effect of Justice Perceptions on Job Satisfaction Among Hispanic Employees. Hispanic Journal of Behavioral Sciences, 40(4), 486-503. https://doi. org/10.1177/0739986318789123

Inoue, A., Kawakami, N., Tsutsumi, A., Shimazu, A., Tsuchiya, M., Ishizaki, M., ... \& Kivimäki, M. (2009). Reliability and Validity of the Japanese Version of the Organizational Justice Questionnaire. Journal of Occupational Health, 51(1), 74-83. https://doi.org/10.1539/joh.L8042

Jonge, J., Bosma H., Peter, R., \& Siegrist, J. (2000). Job strain, effort-reward imbalance and employee well-being: a large-scale cross-sectional study. Social Science e Medicine, 50(9), 1317-1327.

Judge, T. A., \& Colquitt, J. A. (2004). Organizational Justice and Stress: The Mediating Role of Work-Family Conflit. Journal of Applied Psychology, 89(3), 395-404. https://doi.org/10.1037/0021-9010.89.3.395

Kivimäki, M., \& Kawachi, I. (2015). Work Stress as a Risk Factor for Cardiovascular Disease. Current Cardiology Report, 17(74). https://doi.org/10.1007/ $\underline{\text { s11886-015-0630-8\} }}$

Karasek, R. (1985). Job Content Questionnaire and user's guide. University of Massachusets.

Karasek, R., \& Theörell, T. (1990). Healthy work: stress, productivity and the reconstruction of working life. New York: Basic Books.

Koltermann, I. T. A. P., Tomasi, E., Horta, B. L., \& Koltermann, A. P. (2010). Estresse ocupacional em trabalhadores bancários: prevalência e fatores associados. Revista Saúde, 37(2), 33-48. https://doi.org/10.5902/223658342856

Lim, B. T. H., \& Loosemore, M. (2017). The effect of inter-organizational justice perceptions on organizational citizenship behaviors in construction projects. International Journal of Project Management, 35, 95-106. https://doi. org/10.1016/j.ijproman.2016.10.016

Lima, A. W., Machado, D. Q., Carneiro, J. V. C., \& Macedo, A. K. A. (2019). Estressores e Sintomas do Estresse Ocupacional em Profissionais Bancários: Um estudo em uma Agência Bancária Pública. Revista de Carreiras \& Pessoas, 9(2), 222-236. https://doi.org/10.20503/recape.v9i2.38309

Mendonça, H. (2003). Retaliação organizacional: o impacto dos valores e da justiça (Tese de Doutorado). Universidade de Brasília, Brasil.

Mendonça, H., Pereira, C., Tamayo, A., \& Paz, M. G. T. (2003). Validação fatorial de uma escala de percepção de justiça organizacional. Estudos: Saúde e Vida, 30(1), 111-130.

Mendonça, H., \& Tamayo A. (2004). Percepção de Justiça e Reações Retaliatórias nas Organizações: Análise Empírica de um Modelo Atitudinal. Revista de Administração Científica, 8(2), 117-135. https://doi.org/10.1590/S1415$\underline{65552004000200007}$

Mingoti, S. A. (2005). Análise de dados através de métodos de estatística multivariada: uma abordagem aplicada. Belo Horizonte: Editora UFMG.

Paz, M. G. T., Gosendo, E. E. M., Dessen, M. C., \& Mourão, R. G. V. (2009). Justiça Organizacional e Bem-estar pessoal nas organizações. Revista Estudos, 36(1/2), 95-115. https://doi.org/10.18224/est.v36i1.1020 
Pérez-Rodríguez, V., Topa, G., \& Beléndez, M. (2019). Organizational justice and work stress: The mediating role of negative, but not positive, emotions. Personality and Individual Differences, 151. https://doi.org/10.1016/i. paid.2019.04.047

Petarli, G. B., Zandonade E., Salaroli, L. B., \& Bissoli, N. S. (2015). Estresse ocupacional e fatores associados em trabalhadores bancários, Vitória - ES, Brasil. Ciência e Saúde Coletiva, 20(12), 3925-3934. https://doi. org/10.1590/1413-812320152012.01522015

Poole, W. L. (2007). Organizational Justice as a framework for understanding union-management relations in education. Canadian Journal of Education, 30(3), 725-748. https://doi.org/10.2307/20466660

Santos, E. A., Oliveira, R. M., \& Konopka, R. (2016). Justiça Organizacional e clima ético: percepções dos efeitos no estresse relacionado com o trabalho. Revista Capital Cientifico - Eletrônica (RCCe), 14(3). https://doi. org $/ 10.5935 / 2177-4153.20160021$

Siegrist, J., Wege, N., Pühlhofer, F., \& Wahrendorf, M. (2009). A short generic measure of work stress in the era of globalization: effort-reward imbalance. Int Arch Occup Environ Health, 82(8), 1005-1013. https://doi.org/10.1007/ $\underline{\mathrm{s} 00420-008-0384-3}$

Silva, E. R. Z. (2010). O papel da estratégia de defesa nas vivências de prazer e sofrimento no trabalho em uma autarquia federal. Em M. J., Pantoja, M. R. S., Camões, \& S. T. Bergue, Gestão de Pessoas: bases teóricas e experiências no setor público. Brasília: ENAP.

Soares M. B., Mafra S. T. C., \& Farias E. R. (2018). Validation of a Scale of Perceived Stress in Higher Education Professors. REUNA, 23(1), 1-19.

Theörell, T., Perski, A., Akerstedt, T., Sigala, F., Ahlberg-Hultén, G., Svensson, J. \& Eneroth, P. (1988). Changes In Job Strain In Relation to Changes in Psysiological state. Scandinavian Journal Work Environmental Health, 14, 189-96. https://doi.org/10.5271/sjweh.1932

Wang, H., Lu, C., \& Siu, O. (2015). Job Insecurity and Job Performance: The Moderating Role of Organizational Justice and the Mediating Role of Work Engagement. Journal of Applied Psychology, 100(4), 1249-1258. https://doi. org/10.1037/a0038330

Zarife, P. S. (2016). Cidadania organizacional na perspectiva dos direitos e deveres e sua relação com justiça e estresse organizacional (Tese de Doutorado). Universidade de Brasília, Brasil. 